\title{
Afyonkarahisar bölgesi şartlarında bulut hareketlerinin gökyüzü sınıfları tabanlı tahmini
}

\author{
Sky class based prediction of cloud movements in Afyonkarahisar region \\ conditions
}

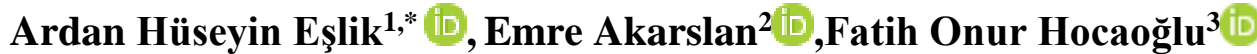 \\ 1,2,3 Afyon Kocatepe Üniversitesi, Elektrik Mühendisliği Bölümü, 03204, Afyonkarahisar Türkiye
}

\section{Özet}

Güneş enerjisinin kesikli ve değişken yapıda olması verimli kullanımını oldukça zorlaştırmaktadır. Bu kesiklilik ve değiş̧enliğin oluşmasındaki en büyük etmen bulut hareketleridir. Gerçekleștirilen çalıșmada, bulutların takibi ve hareketlerinin tahmini için akış tabanlı bir algoritmanın performans1 Afyonkarahisar bölgesi şartlarında araştırılmıştır. $\mathrm{Bu}$ amaç doğrultusunda Afyon Kocatepe Üniversitesi Mühendislik Fakültesine bir dijital kamera yerleștirilmiş ve belirli aralıklarla gökyüzü görüntüleri kaydedilmiştir. Elde edilen görüntüler üzerinde bulut ve gökyüzü sınıflandırmaları gerçekleştirilmiştir. Bulutların takibinin gerçekleştirilebilmesi için takibe en uygun köşe noktaları Shi-Tomasi algoritması kullanılarak belirlenmiştir. Bulunan köşe noktaları Lucas-Kanade optik akış algoritması kullanılarak sıralı görüntüler üzerinde takip edilmiş ve doğrusal regresyon yardımıyla bulutların hareket yön ve hız bilgilerine ulaşılmıştır. Son olarak, ilgili hareket yön ve hız bilgilerinin kullanılmasıyla 340 saniye zaman ufku için 20 saniye çözünürlüğünde bulut hareketleri tahmin edilmiştir. Çalışmada kullanılan veri seti için \%5.88'lik hata performansı ile tahminler gerçekleştirilmiştir. Yöntem, bulut hareketi tahmininde yüksek potansiyele sahip olduğunu göstermiştir

Anahtar kelimeler: Bulut hareketi takibi, Bulut hareketi tahmini, Shi-Tomasi algoritması, Lucas-Kanade optik akış, Güneş enerjisi

\section{Giris}

Güneş enerjisi doğaya zarar vermeyen, en önemli yenilenebilir enerji kaynaklarından biridir. Güneşten elde edilecek enerji büyük oranda güneş ışınım değerine bağlıdır. Yeryüzüne ulaşan güneş 1 şınım değerinin yüksek değişkenliğe sahip olması, güneş enerji santrallerinin çıkış gücünü kararsız hale getirmektedir. Bu kararsızlık, güneş enerji santrallerinin elektrik şebekesine entegrasyonunu zorlaştırmakta ve elektrik şebekesinin güvenliğini, istikrarını ve ekonomik işleyişini önemli ölçüde etkilemektedir. Güneş 1şınımında yaşanan bu değişim ve kesintilerin beraberinde getirdiği çıkış gücü kararsızlıklarının oluşumundaki en büyük etken bulutlardır. Bulutların güneşin önünü kapatmasıyla birlikte güneş 1şınım şiddetinde ani düşüşler meydana gelebilmektedir. Bu gibi durumlarda herhangi bir

\section{Abstract}

The intermittent and variable nature of solar energy makes its efficient use very difficult. The biggest factor in this intermittency and variability is cloud movements. In the study, the performance of a flow-based algorithm for tracking and predicting the movements of clouds was investigated under the conditions of the Afyonkarahisar region. For this purpose, a digital camera was installed in Afyon Kocatepe University Engineering Faculty and sky images were recorded at regular intervals. Cloud and sky classifications were made on the images obtained. In order to follow the clouds, the most suitable corner points for tracking were determined using the Shi-Tomasi algorithm. The corner points found were followed on sequential images using the Lucas-Kanade optical flow algorithm and the motion direction and speed information of the clouds were obtained with the help of linear regression. Finally, using the relevant motion direction and velocity information, cloud motions with a resolution of 20 seconds for a time horizon of 340 seconds are estimated. For the data set used in the study, estimates were made with an error performance of $5.88 \%$. The method has shown that it has a high potential in cloud motion prediction

Keywords: Cloud motion tracking, Cloud motion prediction, Shi-Tomasi algorithm, Lucas-Kanade optical flow, Solar energy

kesinti veya dalgalanma yaşanmaması için güç sistemi operatörünün gerekli güç ihtiyacını farklı yaklaşımlar ile telafi etmesi gerekmektedir. Dolayısıyla güneş 1şınımı değerinin ani düşüş göstereceği zamanların önceden bilinmesi, güç sistemi operatörlerinin faydalarını artırarak güneş enerji santrallerini daha iyi yönetmelerine yardımcı olacaktır.

Meteorolojik veriler geniş alanlar ve uzun süreler için hava tahmin modellerini kapsamaktadır. Ancak bu güneş enerjisi santralleri için yeterli olmayabilir. Örneğin meteorolojik verilere göre açık ve güneşli olması beklenen bir günde güneş 1 şı̆̆ı bulutlar tarafından kısmi veya tam olarak kesintilere uğrayabilir. Bunun sonucunda o bölgede bulunan güneş enerjisi santralinin çıkış gücü büyük oranda etkilenebilir. $\mathrm{Bu}$ nedenle meteorolojik tahminlere oranla

\footnotetext{
* Sorumlu yazar / Corresponding author, e-posta / e-mail: Ardanhuseyineslik@gmail.com (A. H. Eşlik)

Geliș / Recieved: 01.02.2021 Kabul / Accepted: 13.10.2021 Yayımlanma / Published: 14.01.2022

doi: $10.28948 /$ ngmuh.872533
} 
daha yerel ve yüksek çözünürlüğe sahip tahmin modellerine ihtiyaç duyulmaktadır.

Gerçekleştirilen çalışmada esas olarak güneş 1şınımı tahmini hedeflenmektedir. Ancak bu makalede güneş 1şınımı tahmini öncesinde yapılması gereken ön işlemlere odaklanılmıştır. $\mathrm{Bu}$ kapsamda güneş 1şınımı değişkenliğindeki en büyük faktör olan bulutların takibi ve hareket tahminleri gerçekleştirilmiştir. İlerleyen çalışmalarda bulut hareketi tahminlerinin kullanılmasıyla güneş 1şınımı tahminlerinin gerçekleştirilmesi planlanmaktadir.

Gün içerisindeki yüksek güneş 1şınımı değişimlerinin olumsuz etkilerini en az düzeye indirmek ve güneş enerjisinden en etkin şekilde yararlanabilmek amaciyla gelişmiş tahmin yöntemleri, esnek üretim veya yük sağlama, akü bankaları bağlama gibi yaklaşımlar kullanılmaktadır. $\mathrm{Bu}$ yaklaşımlar içerisinde en uygun maliyetli olan çözüm gelişmiş güneş 1şınımı tahmin yöntemleri kullanmaktır. Elde edilecek güneș ışınımı tahmin değerleri kullanılarak üretim değerleri istenilen ölçüde ayarlanabilir ve ihtiyaç duyulan yedek kapasite miktarı azaltılabilir [1, 2].

Güneş 1şınımı tahmini için geçmişten günümüze araştırmacılar tarafından farklı birçok yöntem geliştirilmiş ve kullanılmıştır. Literatürde geliştirilen bu yöntemler incelendiğinde, belirli yöntemlerin belirli zaman ufukları için daha başarılı tahminler gerçekleştirebildiği görülmektedir. Sayısal hava tahmin modelleri 6 saatten birkaç güne kadar başarılı tahminler üretebilirken [3], uydu görüntülerini kullanarak bulut hareketlerini analiz eden tahmin modelleri, 30 dakika ile 6 saat arasındaki zaman ufuklarında daha başarılı tahminler gerçekleştirmektedir [4, 5]. Bir saatin altındaki zaman ufukları için ise geçmiş güneş 1şınımı verilerinin kullanıldığı tahmin modellerinin ve yeryüzünden yüksek açılarla gökyüzü görüntülerini elde etmekte kullanılan gökyüzü görüntüleyicilerinin kullanıldığ tahmin modellerinin daha başarılı sonuçlar verdiği gözlenmiştir [6-8]. Kısa vadeli güneş 1şınımı tahminlerinde detaylı ve yerel bulut bilgisinin bilinmesi tahmin sürecinin genel performansını büyük ölçüde etkilemektedir [9]. Bulut örtüsünün güneş ışınımı üzerine olan etkilerinin incelendiği birçok çalışmada da bulut hareketlerinin güneş 1şınımı değişiminde anahtar unsur olduğu ortaya konulmuştur. [5, $10,11]$.

Bulut hareketlerinin belirlenmesinde gökyüzü görüntüleyicilerinden veya uydudan elde edilen siralı görüntülerden yararlanılmaktadır. Görüntülerin sayısal olarak ifade edilmesinin ardından belirli bir zaman aralığında bulutların gerçekleştirdiği hareketlerin incelenmesi için literatürde farklı teknikler kullanılmıştır. Çapraz korelasyon, fourier dönüşümü kullanılarak çapraz korelasyon, ikili bulut görüntülerinden elde edilen alanları eşleyen algoritma gibi yöntemler kullanılarak bulut hareketleri incelenmiştir [12, 13]. Ayrıca aynı teknikler ile uydu görüntüleri ve gökyüzü görüntüleyicisinden elde edilen görüntülerin eş zamanlı olarak incelenmesiyle kısa ve orta vadeli bulut hareketi ve güneş 1şınımı tahminleri gerçekleştirilmiştir [14]. Sıralı gökyüzü veya uydu görüntülerinde bulut hareketlerini tespit etmenin bir diğer yolu da optik akış algoritmalarından yararlanmaktır. Optik akış, bir görüntüde bulunan nesnelerin hareketinin veya görüntü hızının gözlemciye göre ölçülmesi olarak tanımlanmaktadır [15]. Literatürde bulut hareketlerinin tespitinde optik akış algoritmalarından Lucas-Kanade yöntemini kullanan birçok çalışma bulunmaktadır. WoodBradley ve ark. bulutları mavi ve kırmızı renk kanallarını kullanarak tespit etmiş ve ikili algılama görüntüsü oluşturmuşlardır. Oluşturulan ikili algılama görüntüsü ve Lucas-Kanade yöntemini kullanarak bulut hareketlerini 40 saniyeye kadar tahmin edebilmişlerdir [8]. Benzer şekilde Tuominen ve Tuononen çalışmalarında gökyüzü görüntüleyicisi ile toplanan sıralı görüntülerde bulut hareketlerini Lucas-Kanade yöntemiyle incelemiş ve Yapay Sinir Ağları yöntemini kullanarak bulut hareket tahmini gerçekleştirmişlerdir [16]. Idder ve Laachfoubi gökyüzü görüntülerinden bulutların ikili iskelet görüntüsü adını verdikleri görüntülerini çıkartmıştır. Ardından LucasKanade yöntemini kullanarak oluşturulan iskeletin kritik noktalarının takibini sağlamışlardır. [17]. Lucas-Kanade yönteminin haricinde sıralı görüntüler arasındaki optik akışın tahmin edilmesinde farklı algoritmalardan yararlanılan çalışmalar da mevcuttur. Dev ve ark. gökyüzü görüntüleyicileri kullanılarak elde edilmiş sıralı görüntülere Lucas-Kanade ve Horn-Schunck algoritmalarının avantajlarını birleştiren bir optik akış algoritması uygulamışlardır. 5 dakikaya varan zaman ufukları için oldukça başarılı bulut hareketi tahminleri gerçekleştirmişlerdir [18]. Du ve ark. ise 10 dakikalık zaman ufukları için bulut hareketi ve güneş 1şınımı tahminlerini lokal olmayan bir optik akış algoritması kullanarak gerçekleştirmiştir [19].

Gerçekleştirilen çalışmada, optik akış tabanlı bir algoritma kullanılarak bulut hareketi tahminleri gerçekleştirilmiş ve ilgili yaklaşımın performansı ve uygulanabilirliği incelenmiştir. Bu kapsamda ilk olarak gökyüzü/bulut sınıflandırması gerçekleştirilmiştir. Tespit edilen bulutlara ait kenar ve köşelerin sıralı görüntüler üzerinde takibi sonucunda bulut hareketlerine ait hız ve yön bilgilerine ulaşılmıştır. Elde edilen bilgilerin kullanılmasıyla 340 saniyelik zaman ufkunda ve 20 saniye çözünürlükte güneş önü kapalılık/açıklık tahminlerine ulaşılmıştır. Kullanılan yaklaşıma ait akış diyagramı Şekil 1'de verilmiştir. Elde edilen sonuçlar, yöntemin bulut hareketi tahmininde başarılı bir şekilde kullanılabileceğini göstermiştir. İlerleyen çalışmalarda bulut hareket tahminlerinin kullanıldığı güneş 1şınımı tahmin modellerinin geliştirilmesi planlanmaktadır.

Makalenin organizasyonu şu şekilde planlanmıştır: ilk olarak materyal ve metot başlığı altında; kullanılan veri, maskeleme ve bulut tespiti, bulut hareketi takibi ve bulut hareketi tahmini açıklanmıştır. Ardından bulgular ve tartışmalar başlığı altında gerçekleştirilen deneysel çalışmalar ve sonuçlarından bahsedilmiştir. Son olarak sonuç başlığı altında yapılan deneysel çalışmalara ait analiz sonucuna yer verilmiştir.

\section{Materyal ve metot}

\subsection{Kullanılan veri}

Gökyüzü-bulut ayrımının yapılması, bulut hızı ve hareket yönlerinin belirlenmesi görüntü işleme yöntemlerine dayanan teknikler kullanılarak gerçekleştirildiği için 
gökyüzü görüntüleri girdisi oldukça önemli bir yere sahiptir. Gerçekleş̧irilen bu çalışmada kullanılan gökyüzü görüntüleri Afyon Kocatepe Üniversitesi Mühendislik Fakültesine yerleştirilen $8 \mathrm{~mm} \mathrm{F3.5} \mathrm{balık} \mathrm{gözü} \mathrm{merceğine}$ sahip Canon EOS 80D dijital fotoğraf makinesi ile elde edilmiştir. Kullanılan balık gözü lens ile birlikte $167^{\circ}$ 'lik bir görüş açısına ulaşılmıştır. Görüntüler 11:00-16:00 saatleri arasında, $1 / 2500$ s poz süresi, ISO100, RGB ayarları kullanılarak her 20 saniyede bir çekilmiştir ve $1024 \times 768$ piksel çözünürlüğünde JPEG formatında saklanmıştır. Görüntülerin işlenmesi, bulut hareketlerinin takip ve tahmini Python programlama dili kullanılarak gerçekleştirilmiş̧ir. Ayrıca OpenCV açık kaynak bilgisayar görü kütüphanesi ve NumPy bilimsel hesaplama kütüphanesinden yararlanılmıştır [20].

\subsection{Maskeleme ve bulut tespiti}

Belirli aralıklarla toplanan gökyüzü görüntülerinden bulut hızları ve hareket yönlerinin belirlenebilmesi için ilk olarak bulut ve gökyüzünün piksel düzeyinde birbirinden ayrıştırılması gerekmektedir. Havada bulunan moleküllerin kırmızı 1şıktan daha fazla mavi ışık saçmasına karşın, bulutlar mavi ve kırmızı 1şığı benzer oranda saçmaktadır [21]. Bu kapsamda görüntülerdeki bulutların tespit edilmesi için literatürde $[7,22]$ farklı birçok çalışmada da kullanılan kırmızı/mavi oranına dayalı standart bir yaklaşım kullanılmıştır. Bu yaklaşımda, görüntülerdeki her bir piksele ait kırmızı/mavi oranı bulunmakta ve belirli bir eşik değerinin üzerinde olan pikseller bulut, altında olan pikseller ise gökyüzü olarak sınıflandırılmaktadır. Eşik değeri, analiz edilen görüntülerdeki gökyüzü durumuna göre kullanıcı tarafından belirlenmektedir. Görüntü boyutlarına eşit şekilde oluşturulan ikili algılama görüntüsünde eşik değerinin üzerinde değer alan pikseller 255 , altında kalan pikseller ise sıfır değerine ayarlanmıştır. Sonuç olarak bulut olan piksellerin beyaz, gökyüzü olan piksellerin ise siyah olarak gösterildiği ikili algılama görüntüsü elde edilmiştir. Elde edilen ikili algılama görüntüsü bulut hareket tahmininde kullanılmıştır. Ayrıca görüntülerde bulunan güneşin konumu kullanıcı tarafından belirlenmiş ve oluşturulan bir maske yardımıyla sınıflandırılmıştır. İlgili maske kullanılarak güneş, ikili algılama görüntüsünden çıkartılmıştır. Şekil 2'de orijinal gökyüzü görüntüsü ve bu görüntüden elde edilen ikili algılama görüntüsü verilmiştir.

\subsection{Bulut hareketi takibi}

Bulut ve gökyüzü ayrımının yapılması sonrasında bulutların hareket yönlerinin ve hızlarının bulunması gerekmektedir. $\mathrm{Bu}$ amaç doğrultusunda Shi-Tomasi [23] köşe algılama algoritması öznitelik noktalarının bulunması, Lucas-Kanade [15] optik akış algoritması ise seçilen öznitelik noktalarının takibi için kullanılmıştır.

\subsubsection{Takip edilecek noktaların bulunması}

Belirli aralıklarla çekilmiş görüntülerde bulutların takip edilebilmesi için ilk olarak takip edilmeye en uygun öznitelik noktaları belirlenmelidir. Bu öznitelik noktaları yüksek renk geçişleri veya yoğunluğa sahip pikseller olmakla birlikte genellikle nesnelerin köşelerinde bulunmaktadır.

Literatürde öznitelik noktası belirlenmesinde oldukça sık olarak kullanılmakta olan Shi-Tomasi algoritması, Harris ve Stephens'ın geliştirmiş olduğu algoritmada ufak bir değişik yapılmasıyla ortaya çıkmıştır. Harris ve Stephens'ın geliştirdiği algoritmada öncelikle piksel etrafında bir pencere oluşturulmaktadır. Oluşturulan pencerenin farklı yönlerde küçük miktarlarda kaydırılmasıyla görüntüdeki ortalama yoğunluk değişimleri hesaplanmaktadır. Yoğunluk değişim değerlerine göre pikselin kenar, köşe veya düz bir yüzey olduğu belirlenmektedir [24].

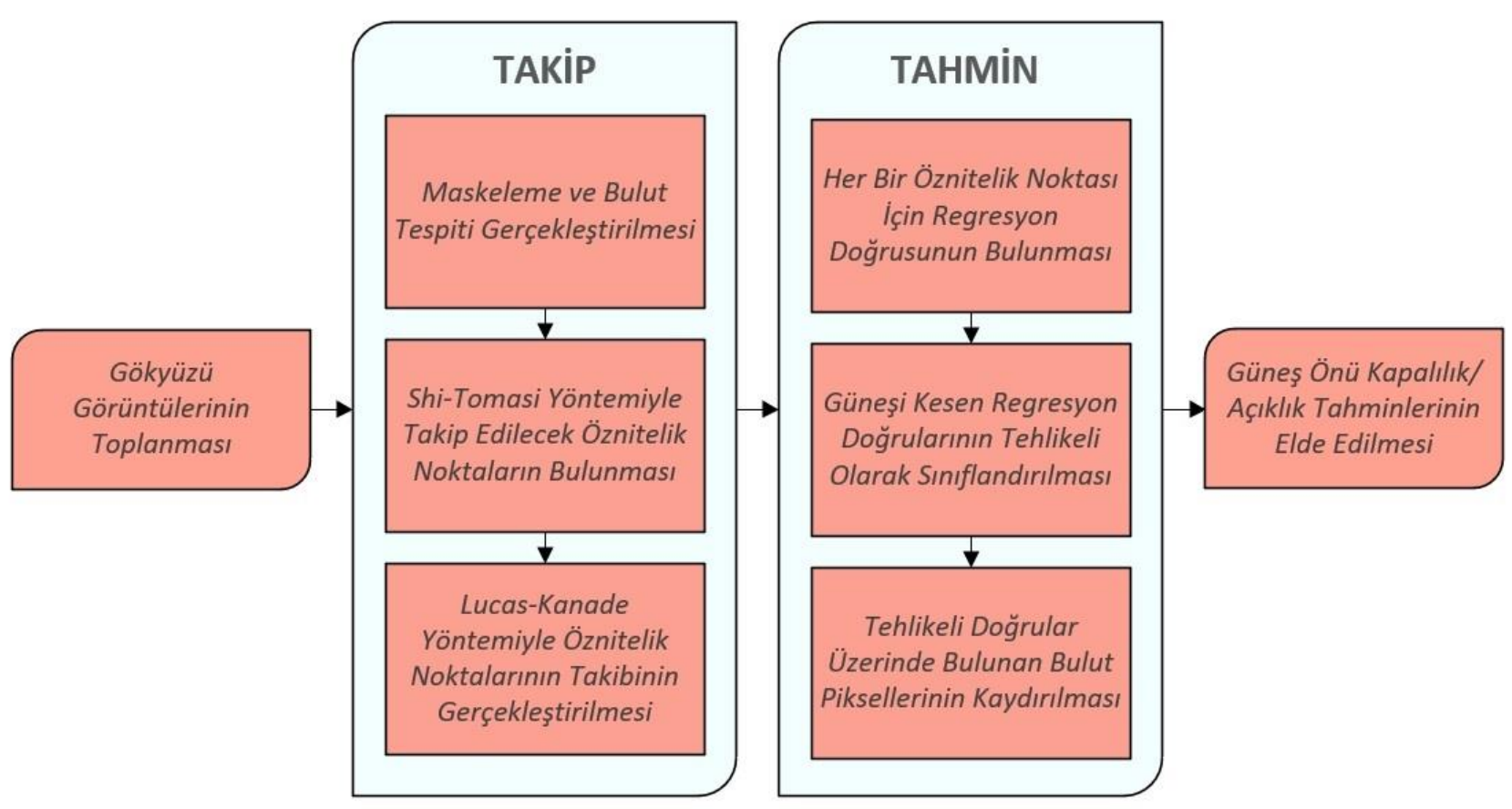

Şekil 1. Kullanılan yaklaşıma ait akış diyagramı 


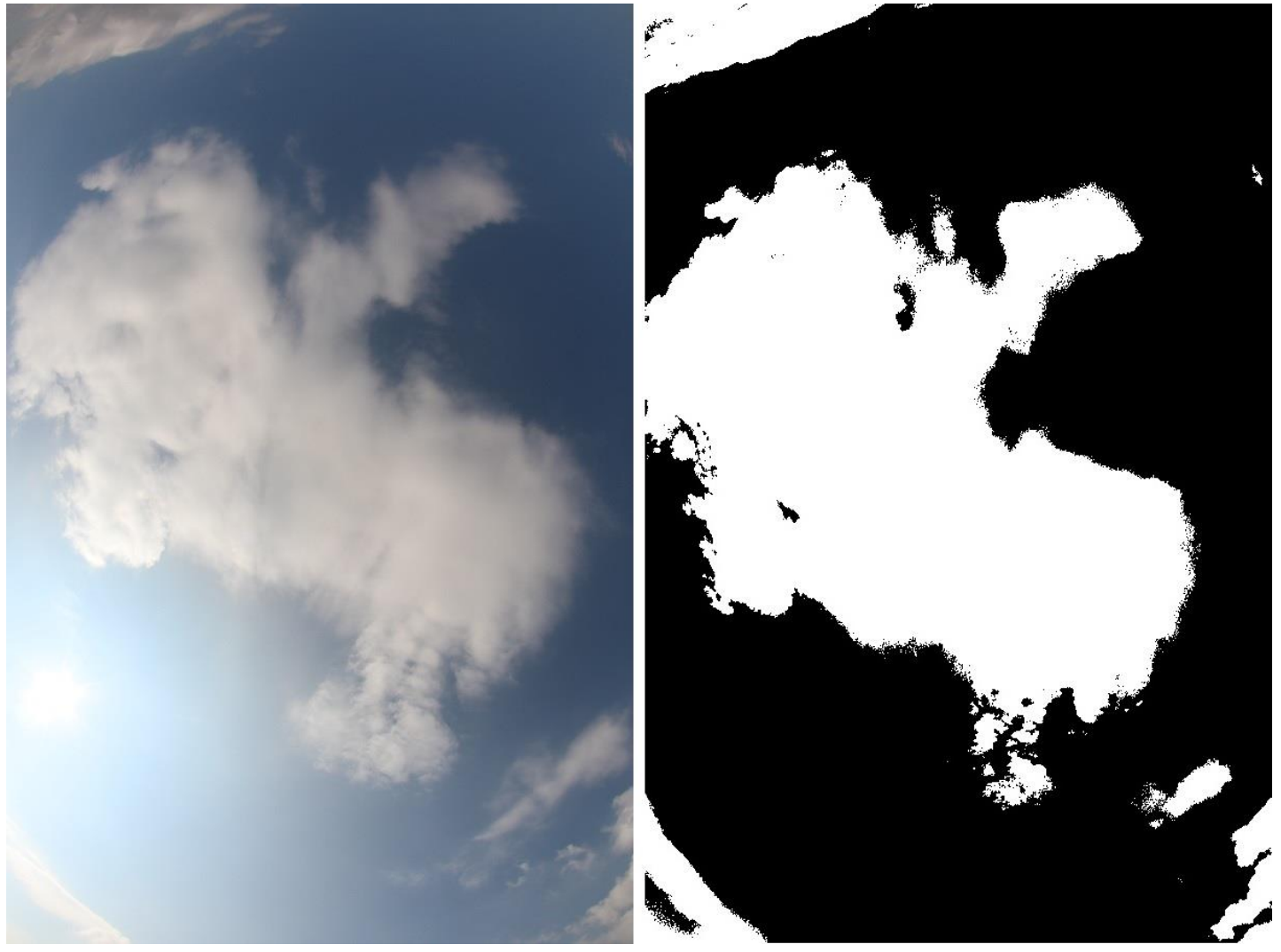

Şekil 2. Gökyüzü orijinal görüntüsü (solda), İkili algılama görüntüsü (sağda)

$(x, y)$ koordinatlarında $I_{(x, y)}$ yoğunluğunda olan bir pikselin, $(u, v)$ kadar kaydırıldığında oluşacak yoğunluk değişimi $E_{(u, v)}$ Denklem (1)'de verilmiştir.

$$
E_{(u, v)}=\sum_{x, y} w(x, y)\left[I_{(x+u, y+v)}-I_{(x, y)}\right]^{2}
$$

Yoğunluk değişimi hesaplamasının ardından her bir pikselin etrafindaki pencere üzerinde Denklem (2)'de formülü verilen otokorelasyon matrisi hesaplanmaktadır. Harris ve Stephens'a göre M otokorelasyon matrisinin iki özdeğeri (eigenvalue) de büyük değerler ise orada bir köşe noktası vardır. Özdeğerlerden birisi çok küçük, diğeri büyükse kenar, ikisi de çok küçükse düz bir yüzey bulunmaktadır.

$$
M=\sum_{x, y} w(x, y)\left[\begin{array}{cc}
I_{x}^{2} & I_{x} I_{y} \\
I_{x} I_{y} & I_{y}^{2}
\end{array}\right]
$$

Harris ve Stephens, özdeğerleri $a$ ve $\beta$ şeklinde gösterilen otokorelasyon matrisinin determinantından belirlenen bir katsayı ile çarpılmış matrisin izini (trace) çıkartan bir fonksiyon önermiştir. Fonksiyon çıktısını ise önceden belirlenen bir eşik değer ile karşılaştırmıştır. Önerilen fonksiyon Denklem (3)'te gösterilmiştir.

$$
\mathrm{R}=\operatorname{Det}(\mathrm{M})-\mathrm{kTr}^{2}=\alpha \beta-\mathrm{k}(\alpha+\beta)^{2}
$$

Shi-Tomasi algoritmasında ise denklem 3 yerine iki özdeğerden küçük olanı önceden belirlenen eşik değeri ile karşılaştıran ve Denklem (4)'teki gibi formülize edilen bir yaklaşım kullanılmaktadır. Elde edilen sonucun eşik değerinden yüksek olması durumunda o noktada bir köşe olduğu anlaşılmaktadır.

$$
\mathrm{R}=\min (\alpha, \beta)
$$

Gökyüzü görüntülerinde bulutların kenarlarında yer alan köşeler oldukça kritik öneme sahiptir. Gerçekleştirilen çalışmada görüntü üzerinde bulunan bu noktalar Shi-Tomasi algoritması kullanılarak tespit edilmiştir. İlgili kenarları ön plana çıkarmak ve bulunmalarını kolaylaştırmak amacıyla görüntünün mavi ve kırmızı renk kanalları arasındaki farkın tek kanallı görüntüsü kullanılmıştır. OpenCV kütüphanesinde yer alan goodFeaturesToTrack() fonksiyonu kullanılarak görüntü üzerinde bulunan takip için en uygun öznitelik noktaları bulunmuş ve konum bilgilerine ulaşılmıştır.

\subsection{2 Öznitelik noktalarının takibi}

Shi-Tomasi algoritması kullanılarak bulunan öznitelik noktaları optik akış algoritmasında girdiler olarak kullanılmaktadır. Optik akış, bir görüntüde bulunan nesnelerin hareketinin veya görüntü hızının gözlemciye göre ölçülmesidir [15]. Bu yaklaşımda her bir pikselin kareler (frame) arasındaki değişimine bakılarak değişimin hızı ve yönü hesaplanmaktadır. Algoritmada akışın başlangıçta sabit olduğu varsayılmaktadır ve ilk olarak yerel komşulara 
bakılmaktadır. Ardından temel optik akış denklemleri kullanılarak tüm piksellerdeki komşular için algoritma çalıştırılmaktadır [25]. İki görüntü arasındaki optik akış Denklem (5)'te verilmiştir. Denklemde $I_{x}, I_{y}, I_{t}$ görüntüdeki konumsal değişimleri gösterirken, $V_{x} \mathrm{x}$ eksenindeki akışı, $V_{y}$ ise y eksenindeki akışı ifade etmektedir.

$$
I_{x} V_{x}+I_{y} V_{y}+I_{t}=0
$$

Literatürde, günümüze kadar optik akışın hesaplanabilmesi için çeşitli yöntemler önerilmiştir. Barron ve ark. gerçekleştirdikleri çalışmada, optik akış tahmininde kullanılan bu yöntemleri incelemiş ve performanslarını karşılaştırmıştır. Karşılaştırma sonucunda, farklı veri setleri üzerinde en güvenilir sonuçları veren yöntemlerden birinin Lucas-Kanade optik akış yöntemi olduğu sonucuna ulaşılmıştır [25]. Gerçekleştirmiş olduğumuz çalışmada optik akışın tahmin edilmesinde, Barron ve ark. elde ettiği bulgular, bulutların yavaş hareketleri ve literatürde yaygın kullanımı dikkate alınarak Lucas-Kanade yöntemi tercih edilmiştir. Lucas-Kanade yöntemi öznitelik noktaları etrafındaki piksellerin çevresinde yerel akış olduğunu ve öznitelik noktası yer değişiminin küçük olduğunu varsaymaktadır [15]. Yöntemin temel algoritması aşağıda maddeler halinde verilmiştir [26].

- İlk olarak gürültü hassasiyetini azaltmak amacıyla giriş görüntüsüne gauss yumuşatması uygulanır.

- Gerçekleştirilen yumuşatma sonrasında konumsal türevler $\left(I_{x}, I_{y}, I_{t}\right)$ hesaplanır.

- Görüntüde bulunan her bir piksel için türevsel erișim hesaplanır. Denklem (6) kullanılarak t anındaki yerel görüntü akışı hesaplanır. Denklemde yer alan $\mathrm{p}$ bir pikseli, $p_{1}, p_{2}, \ldots, p_{n}$ ise $\mathrm{n}$ adet komşu pikseli ifade etmektedir.

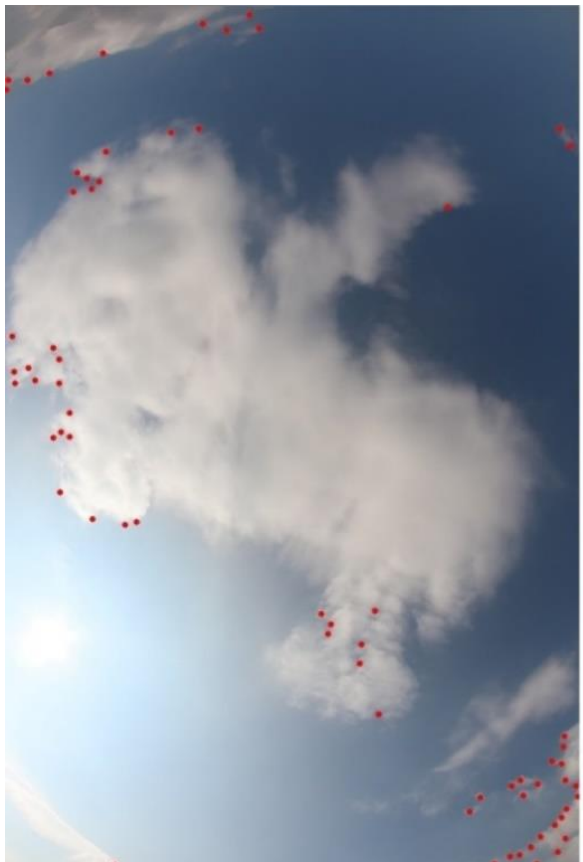

$$
\begin{gathered}
I_{x}\left(p_{1}\right) V_{x}+I_{y}\left(p_{1}\right) V_{y}+I_{t}\left(p_{1}\right)=0 \\
: \\
I_{x}\left(p_{n}\right) V_{x}+I_{y}\left(p_{n}\right) V_{y}+I_{t}\left(p_{n}\right)=0
\end{gathered}
$$

- $\quad$ Denklem (6) matris formunda Denklem (7)'deki gibi ifade edilebilir.

$$
A=\left|\begin{array}{cc}
I_{x}\left(p_{1}\right) & I_{y}\left(p_{1}\right) \\
\vdots & \vdots \\
I_{x}\left(p_{n}\right) & I_{y}\left(p_{n}\right)
\end{array}\right|, v=\left|\begin{array}{l}
V_{x} \\
V_{y}
\end{array}\right|, b=\left|\begin{array}{c}
-I_{t}\left(p_{1}\right) \\
\vdots \\
-I_{t}\left(p_{n}\right)
\end{array}\right|
$$

- Son olarak iki görüntü arasındaki optik akışı hesaplamak için Denklem (8) en küçük kareler yaklaşımı kullanılarak çözülür. $A^{T}$, A matrisinin transpozunu ifade etmektedir.

$$
v=\left(A^{T} A\right)^{-1} A^{T} b
$$

Lucas-Kanade yönteminin uygulanmasında OpenCV kütüphanesinde yer alan calcOpticalFlowPyrLK() fonksiyonundan yararlanılmıştır. Fonksiyon, takip edilmek istenen öznitelik noktalarının bir sonraki karede bulunduğu yerleri tespit ederek yeni koordinat bilgilerini geriye döndürmektedir. Sıralı olarak çekilen görüntüler üzerinde kaç kare boyunca öznitelik noktası takibi gerçekleştirileceği kullanıcı tarafından belirlenmektedir. Çalışmamızda öznitelik noktalarının takibi sıralı olarak çekilen 5 kare boyunca gerçekleştirilmiştir ve her bir aşamadaki koordinat bilgileri kaydedilmiştir. Şekil 3'te Shi-Tomasi algoritması kullanılarak bulunan öznitelik noktaları ve bu noktaların sıralı 2 kare boyunca gerçekleștirmiş olduğu hareketler görülebilmektedir.

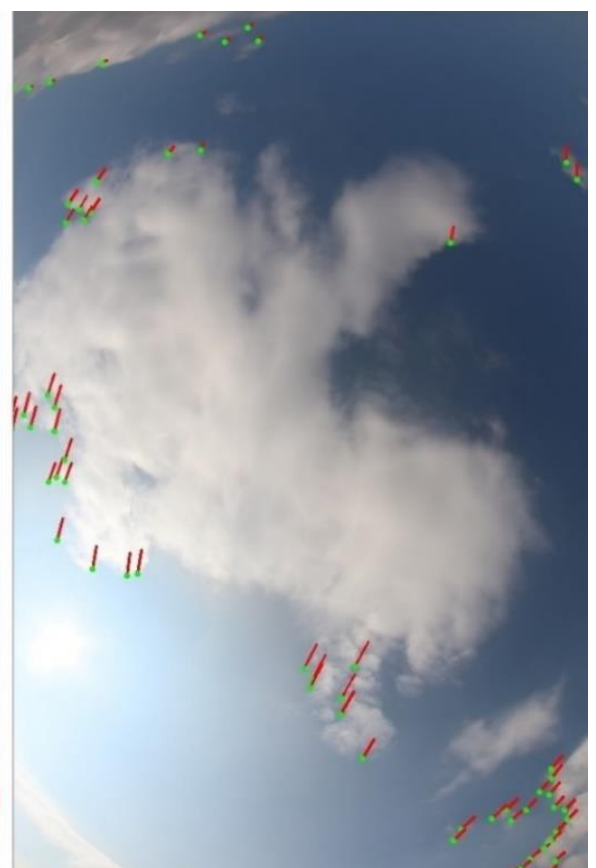

Șekil 3. Shi-Tomasi algoritması kullanılarak bulunan öznitelik noktaları (solda), Bulunan öznitelik noktalarının sıralı karelerde takibinin gerçekleştirilmesi (sağda) 


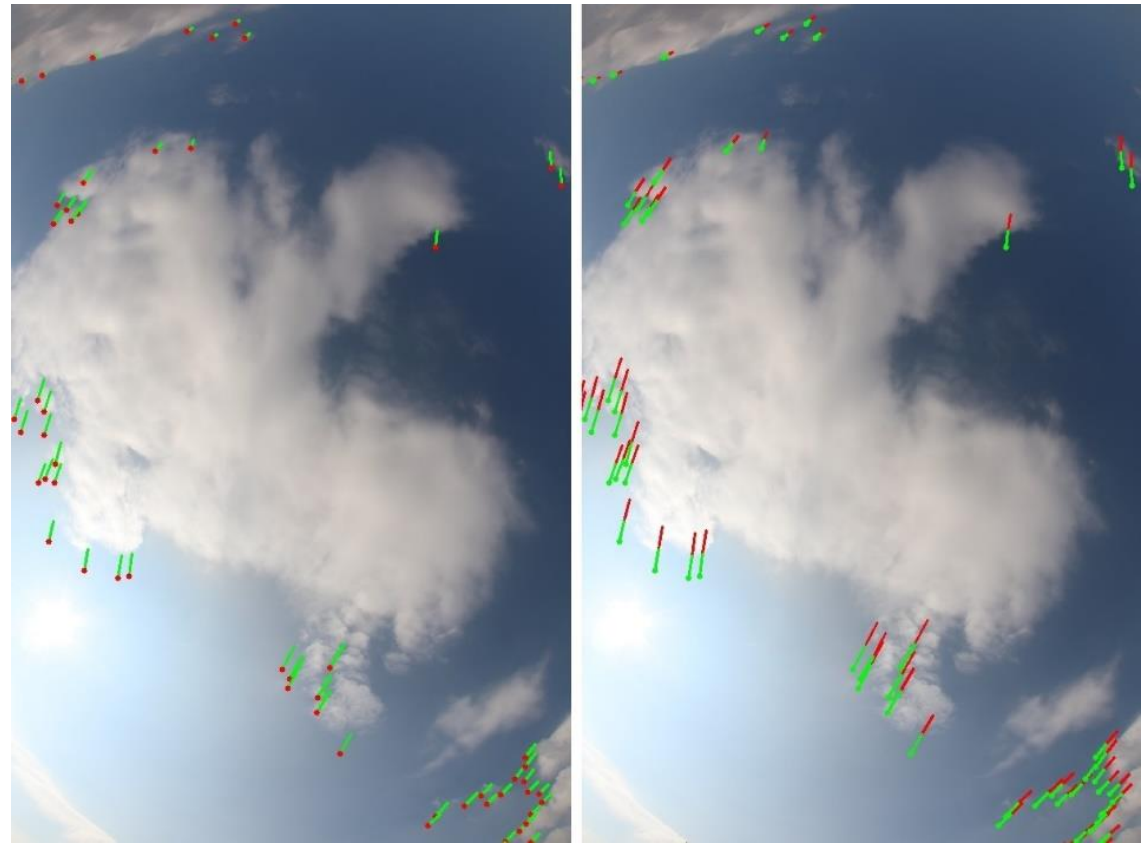

Şekil 4. Öznitelik noktalarının 1 kare sonrası gerçekleştireceği hareketlerin tahmini (solda), Öznitelik noktalarının 1 kare sonrası gerçekleştireceği hareketlerin tahmini ve geçmiş karelerdeki hareketleri (sağda)

\subsection{Bulut hareketi tahmini}

Bulut hareket tahmininin gerçekleștirilebilmesi için ilk olarak öznitelik noktalarına ait hızların ve hareket yönlerinin bulunması gerekmektedir. $\mathrm{Bu}$ kapsamda takibi gerçekleştirilen her bir öznitelik noktası için önceki karelerde bulunduğu tüm konumlarını kesen bir doğrusal regresyon doğrusu hesaplanmıştır. Ardından her bir öznitelik noktasının çizilen regresyon doğrusu üzerinde ilk konumundan son konumuna kadar kat ettiği mesafe bulunmuştur. Bulunan mesafelerin görüntü takibi gerçekleştirilen kare sayısına bölünmesiyle birlikte her bir öznitelik noktasının bir karedeki hızına ulaşılmıştır. Elde edilen hızlar 20 saniyede bir çekilen gökyüzü görüntüleri nedeniyle saniye/piksel birimine sahiptir. Bulutların farklı yön ve hızlarda hareket edebilmeleri nedeniyle bulunan her bir öznitelik noktası için hız ve yönlerin ayrı ayrı hesaplanması oldukça önemlidir. Böylelikle bulutların yapabileceği farklı yön ve hızlardaki hareketlerin yakalanabilmesi ve tahminlerinin gerçekleştirilmesi mümkün olabilmektedir.

Her bir öznitelik noktasına ait regresyon doğrusunun bulunmasının ardından bulut tespiti aşamasında elde edilen ikili algılama görüntüsü kullanılarak bulut hareket tahminleri gerçekleştirilmiştir. $\mathrm{Bu}$ amaç doğrultusunda ilk olarak çizilen regresyon doğrularının güneşi kesip kesmediği kontrol edilmiştir. Güneşi kesen regresyon doğrularındaki bulutların güneşin önünü kapatma ihtimalinin yüksek olmasından dolayı bu doğrular tehlikeli olarak sınıflandırılmıştır. Tehlikeli regresyon doğru veya doğruları üzerinde bulunan her bir pikselin koordinat bilgileri alınarak ikili algılama görüntüsünde aynı koordinat üzerinde bulunan pikselin bulut veya gökyüzü olması durumu incelenmiştir. Bulut durumunda olan piksellerin ilgili regresyon doğrusu üzerinde hesaplanan hız değeri kadar kaydırılmasıyla bir sonraki karede bulunacağ 1 yerler tahmin edilmiștir. Bir kare sonrası için gerçekleştirilen bu işlemin kullanıcı tarafından belirlenen tekrar sayıs kadar arka arkaya gerçekleştirilmesiyle daha uzun süreli tahminler elde edilmiştir. Şekil 4'te bulunan öznitelik noktalarının 1 kare sonra gerçekleştireceği hareketlerin tahmini ve geçmiş karelerdeki hareketleri verilmiştir.

\section{Bulgular ve tartışma}

Gerçekleştirilen çalışmada algoritmanın başarısının değerlendirilmesi amacıyla Afyon Kocatepe Üniversitesi Mühendislik Fakültesine yerleştirilen kamera aracılığı ile toplanan gökyüzü görüntüleri incelenmiş ve deneyde kullanılması uygun görülen 20 adet sıralı görüntü belirlenmiștir. Güneșin gün boyunca bulutlar tarafindan kapalı kaldığ 1 veya hiç bulutun olmadığı günlerde elde edilen fotoğraflar değerlendirmeye alınmamıştır. Bununla birlikte algoritma performansının daha net olarak görülebilmesi amacıyla güneşin önünün ilk olarak açık olduğu, belirli bir zaman sonrasında bulutlar tarafından kapatıldığı görüntüler tercih edilmiştir. $\mathrm{Bu}$ şartlar altında oluşturulan veri seti algoritmaya sokularak bulut hareketi tahmin sonuçları elde edilmiştir. Bulutların yaptıkları hareketlerin ve hızlarının daha kararlı olarak değerlendirilebilmesi amacıyla veri setinin tahmininde 3 görüntü kullanılmıştır. İlk görüntü üzerinde takip edilecek noktalar ve koordinatları tespit edilmiştir. Sonraki iki görüntüde ise ilk görüntüde bulunan noktaların yaptığı hareketler takip edilmiştir. Veri setinde geriye kalan 17 gökyüzü görüntüsü ise test amaçlı kullanılmış ve tahmin sürecine dahil edilmemiştir. Tahminler, gökyüzü görüntülerinin 20 saniyelik aralıklarla toplanması nedeniyle 20 saniyelik zaman ölçeğinde gerçekleştirilmiştir. $\mathrm{Bu}$ sayede test için ayrılan her bir görüntüdeki bulutluluk durumları kontrol edilerek algoritmanın performansı incelenebilmiştir. İleride 
gerçekleştirilecek çalışmalarda görüntülerin daha sık aralıklarla toplanması ve tahmin çözünürlüğünün arttırılması hedeflenmektedir.

Algoritmaya verilen görüntülerde bulunan güneşin konumu kullanıcı tarafindan tespit edilerek maske yardımıyla işaretlenmiştir. Elde edilen regresyon doğrularının tehlikeli doğru olarak sınıflandırılmasında ve güneşin önünün kapanacağı sürenin hesaplanmasında bu maskelerden yararlanılmıştır. Şekil 5'te kullanılan veri seti için 340 saniyelik zaman ufkunda gerçekleştirilen tahmin sonuçları verilmiştir.

Gerçekleştirilen tahmin sonuçları incelendiğinde, kullanılan veri seti için algoritmanın sonraki 80 saniyeye kadar (4 kare sonrası) doğru tahminler yapabildiği görülmektedir. Ancak güneşin önünün 120. saniyeden sonra kapanacağı öngörülmesine karşılık güneşin önü 100. saniye yani 5. karede kapanmıştır. 100-120. saniye aralıklarında tespiti nispeten daha zor olan seyrek ve düşük kalınlıklardaki bulutların yoğun olarak bulunması nedeniyle bazı bulutlar algoritma tarafından gökyüzü olarak tanımlanmış ve bu nedenle bu saniyelerde güneşin önü açık olarak tahmin edilmiştir. Sonraki karelerde güneşin önü bulutlar tarafından sürekli kapalı kalmış, bu süreç ise algoritma tarafından doğru tahmin edilmiştir. Sonuç olarak veri setinde \%5,88'lik makul oranında bir hata ile tahminler gerçekleştirilebilmiştir.

Literatürde, Jaouhari ve arkadaşları gerçekleştirdikleri çalışmada bulut hareketi takibinde Harris kenar ve köşe belirleme yöntemi ile Lucas-Kanade optik akış yöntemini kullanmışlardır [27]. Çalışmada kullanılan yaklaşımın başarısının değerlendirilebilmesi amacıyla Jaouhari ve arkadaşları tarafından kullanılan yaklaşım veri setine uygulanmış ve sonuçlar Tablo 1'de sunulmuştur.

Tabloda verilen sonuçlar incelendiğinde, Jaouhari ve arkadaşları tarafından kullanılan yaklaşım ile makalemizde kullanılan yaklaşımın aynı hata oranları ile tahminler gerçekleştirebildiği görülmektedir. Ancak takip edilecek öznitelik noktalarının tespit edilmesi aşamasında, Harris kenar ve köşe belirleme yönteminin kullanılması fazladan 10 nokta belirlenmesine neden olmuştur. $\mathrm{Bu}$ öznitelik noktalarının oluşturduğu işlem yükü ve karmaşıklığı göz önüne alındığında, bulut hareketi tahmininde makalemizde yer alan yaklaşımın kullanılmasının daha uygun olduğu sonucuna varılmıştır. İleride yapılması planlanan çalışmalarda farklı hava şartları altında yaklaşımın tahmin performansının değerlendirilmesi, tahmin çözünürlüğünün arttırılması hedeflenmektedir. İlave olarak, elde edilen güneş önü kapalılık/açıklık bilgilerinin kullanılmasıyla daha başarılı güneş ışınımı tahmin modellerinin oluşturulması planlanmaktadır.

Tablo 1. Sonuçların karşılaştırılması

\begin{tabular}{ccc}
\hline Kullanılan Yaklaşım & $\begin{array}{c}\text { Tespit Edilen } \\
\text { Öznitelik } \\
\text { Noktası Sayısı }\end{array}$ & Hata Oranı \\
\hline Shi-Tomasi / Lucas - Kanade & 70 & $\% 5.88$ \\
Harris / Lucas - Kanade & 80 & $\% 5.88$ \\
\hline
\end{tabular}

Deney sonucunda, 340 saniye gibi uzun bir zaman ufku için başarılı tahminler yapılabildiği görülmektedir. Ayrıca her bir kare arasındaki yavaş hareketleri nedeniyle bulutların takibinde Lucas-Kanade yönteminin oldukça kullanışlı olduğu sonucuna varılmıştır. Öznitelik noktalarının belirlenmesinde görüntünün mavi ve kırmızı renk kanalları arasındaki farkın tek kanallı görüntüsünün kullanılması bulut köşelerini vurgulayarak tespit edilen gereksiz öznitelik noktası sayısını en aza indirmiştir. Yeterli sayıda öznitelik noktasının belirlenmesiyle algoritma riskli bulutları tespit edebilmektedir. Gökyüzü ve bulut tespiti aşamasında seyrek ve düşük kalınlıklardaki bulutların da daha yüksek oranlarda tespit edilebilmesiyle yöntemin başarısı arttırılabilir. Ayrıca güneşin maskelenmesinde farklı görüntü işleme yöntemlerinden yararlanılarak gökyüzü görüntüsü güneş, bulut ve gökyüzü olarak sınıflandırılabilir. Sonuç olarak algoritma, geliştirmeye açık olan yönleriyle birlikte bulut hareketi tahmininde başarılı sonuçlar üretebilmiş ve güneş ışınımı tahmini için yüksek potansiyele sahip olduğunu göstermiştir.

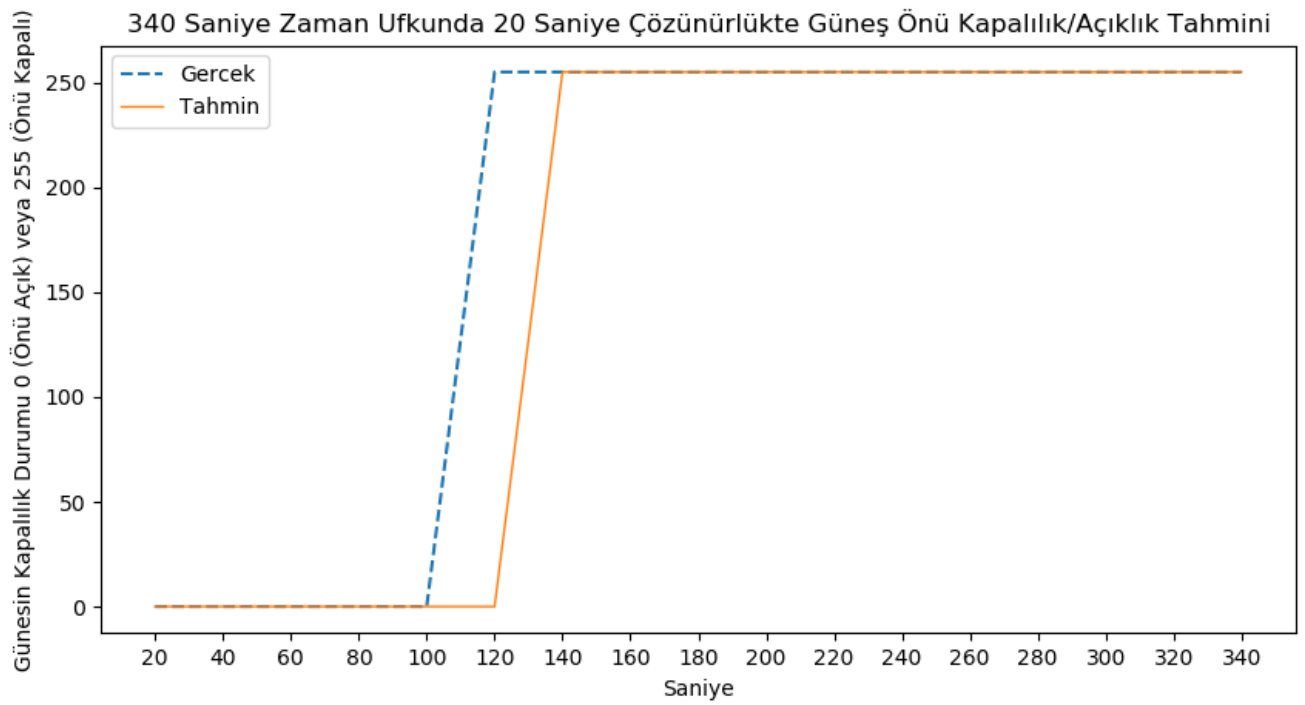

Şekil 5. Veri seti için 340 saniye zaman ufkunda 20 saniye ölçekli gerçekleştirilen güneş önü kapalılık/açıklık tahmini 


\section{Sonuçlar}

$\mathrm{Bu}$ çalı̧̧̧mada, bulut hareketi tahmini için optik akış tabanlı bir algoritma kullanılarak yöntemin performansı ve uygulanabilirliği incelenmiștir. İlgili yöntem kullanılarak 340 saniye zaman ufku için 20 saniye çözünürlüğünde bulut hareketi tahminleri gerçekleştirilmiştir. İncelemede Afyon Kocatepe Üniversitesi Mühendislik Fakültesine yerleştirilen dijital fotoğraf makinesinden 20 saniyede bir elde edilen gökyüzü görüntüleri kullanılmıştır. Görüntüler üzerinde ilk olarak bulut, gökyüzü sınıflandırılması gerçekleştirilmiş, ardından Shi-Tomasi algoritması kullanılarak tespit edilen köșe noktaları Lucas-Kanade optik akış algoritması yardımıla takip edilmiştir. Yöntem, belirlenen veri seti üzerinde test edilmiştir ve $\% 5.88^{\prime}$ lik hata oranıyla tahminler gerçekleştirmiştir. Tahmin ufkunun artmasıyla doğru orantılı olarak gerçekleştirilen tahminlerin zorluğu da $\operatorname{arttığ~}$ düşünüldüğünde bulunan $\% 5.88^{\prime}$ lik hata oranı yöntemin yüksek potansiyele sahip olduğunu göstermektedir. Bununla birlikte farklı yön ve hızlarda hareket eden bulutların takip ve tahminini başarılı bir şekilde gerçekleştirebilmiştir. İlerleyen çalışmalarda, güneşin farklı görüntü işleme yöntemleri kullanılarak sınıflandırılması ve geliştirilecek bir yöntem ile takip edilecek öznitelik noktalarının belirli aralıklarla güncellenmesi planlanmaktadır. Böylelikle sürekli bir tahmin algoritmasına sahip olunması hedeflenmektedir. Gerçekleştirilen bu çalışma sonucunda elde edilen tahmin sonuçlarının kullanılmasıyla güneş ıșınımı değişiminde en büyük role sahip olan bulutların tahmin sürecine dâhil edilmesi ve bu sayede daha başarılı güneş 1şınımı tahmin modelleri geliştirilmesi planlanmaktadır.

\section{Çıkar çatışması}

Yazarlar çıkar çatışması olmadığını beyan etmektedir.

\section{Benzerlik oranı (iThenticate): $\% 6$}

\section{Teşekkür:}

$\mathrm{Bu}$ çalışma, Afyon Kocatepe Üniversitesi Bilimsel Araştırma Projeleri birimi tarafından 20.FENBİL.25 no'lu proje kapsamında desteklenmiştir. Desteklerinden dolayı Afyon Kocatepe Üniversitesi Bilimsel Araştırma Projeleri birimine teşekkür ederiz.

\section{Kaynaklar}

[1] V. Kostylev and A. Pavlovski, Solar power forecasting performance-towards industry standards. 1st international workshop on the integration of solar power into power systems,pp.1-8, Aarhus, Denmark, 2011.

[2] L. Bird, M. Milligan and D. Lew, Integrating variable renewable energy: challenges and solutions. National Renewable Energy Laboratory (NREL), Golden Colorado, United States, Technical Report NREL/TP6A20-60451, 2013. https://doi.org/10.2172/1097911

[3] L. M. Aguiar, B. Pereira, P. Lauret, F. Díaz and M. David, Combining solar irradiance measurements, satellite-derived data and a numerical weather prediction model to improve intra-day solar forecasting. Renew. Energy, 97, 599-610, 2016. https://doi.org/10.1016/j.renene.2016.06. 018

[4] H. M. Diagne, P. Lauret and M. David, Solar irradiation forecasting: state-of-the-art and proposition for future developments for small-scale insular grids. WREF 2012-World Renewable Energy Forum, May 2012.

[5] J. Alonso-Montesinos and F. J. Batlles, The use of a sky camera for solar radiation estimation based on digital image processing. Energy, 90, 377-386, 2015. https://doi.or g /10.1016/j.energy.2015.07.028

[6] C. W. Chow, B. Urquhart, M. Lave, A. Dominguez, J. Kleissl, J. Shields and B. Washom, Intra-hour forecasting with a total sky imager at the UC San Diego solar energy testbed. Solar Energy, 85 (11), 28812893, December,

2011. https://doi.org/10.1016/j.solener. 2011.08 .025

[7] M. Cervantes, H. Krishnaswami, W. Richardson, and R. Vega, Utilization of low cost, sky-imaging technology for irradiance forecasting of distributed solar generation. 2016 IEEE Green Technologies Conference (GreenTech), pp. 142-146, Kansas City, United States, 2016. https: //doi.org/10.1109/GreenTech.2016.33

[8] P. Wood-Bradley, J. Zapata and J. Pye, Cloud tracking with optical flow for short-term solar forecasting. Proceedings of the 50th Conference of the Australian Solar Energy Society, Melbourne, 2012.

[9] R. Chauvin, J. Nou, S. Thil, A. Traoré and S. Grieu, Cloud detection methodology based on a sky-imaging system. Energy Procedia, 69, 1970-1980, 2015. https://doi .org/10.1016/j.egypro.2015.03.198

[10] J. Alonso, A. Ternero, F. J. Batlles, G. López, J. Rodríguez and J. I. Burgaleta, Prediction of cloudiness in short time periods using techniques of remote sensing and image processing. Energy Procedia, 49, 2280-2289, 2014. https://doi.org/10.1016/j.egy pro.2014.03.241

[11] F. J. Batlles, J. Alonso and G. López, Cloud cover forecasting from METEOSAT data. Energy Procedia, 57, 1317-1326, 2014. https://doi.org/10.1016/j. egypro.2014.10.122

[12] J. A. Leese, C. S. Novak and V. Ray Taylor, The determination of cloud pattern motions from geosynchronous satellite image data. Pattern Recognit, 2(4), 279-292, December 1970. https://doi.org/10.1016/0031-32 03(70)90018-X

[13] R. Chauvin, J. Nou, S. Thil and S. Grieu, Cloud motion estimation using a sky imager. AIP Conference Proceedings, 1734(1), 150003, 2016. https://doi.org/10.10 63/1.4949235

[14] J. Alonso and F. J. Batlles, Short and medium-term clou diness forecasting using remote sensing techniques and sky camera imagery. Energy, 73, 890-897, 2014. https://doi .org/10.1016/j.energy.2014. 06.101

[15] B. Lucas and T. Kanade, An iterative image registration technique with an application to stereo vision. Proceedings DARPA Image Understanding Workshop, pp. 121-130, April 1981. 
[16] P. Tuominen and M. Tuononen, Cloud detection and movement estimation based on sky camera images using neural networks and the Lucas-Kanade method. AIP Conference Proceedings, 1850(1), 140020, 2017. https://doi. org/ 10.1063/1.4984528

[17] H. I. Ben Idder and N. Laachfoubi, Cloud motion estimation in satellite image sequences by tracking skeleton critical points using lucas-kanade method. 13th International Conference on Computer Graphics, Imaging and Visualization (CGiV), pp. 178-183, 2016. https://doi.org/ 10.1109/CGi V.2016.42

[18] S. Dev, F. M. Savoy, Y. H. Lee and S. Winkler, Shortterm prediction of localized cloud motion using ground-based sky imagers. IEEE Region 10 Annual International Conference, Proceedings/TENCON, 0, 2563-2566, 2017. https://doi.org/ 10.1109/TEN CON.2016.7848499

[19] J. Du, Q. Min, P. Zhang, J. Guo, J. Yang and B. Yin, Short-term solar irradiance forecasts using sky images and radiative transfer model. Energies, 11(5), 1107, May 2018. https://doi.org/10.3390/ en11051107

[20] G. Bradski and A. Kaehler, Learning OpenCV: Computer vision with the OpenCV library, O'Reilly Media Inc, 2008.

[21] A. Heinle, A. Macke and A. Srivastav, Automatic cloud classification of whole sky images. Atmospheric Measurement Techniques, 3(3), 557-567, 2010. https://doi. org/ 10.5194/amt-3-557-2010
[22] H. Huang, J. Xu, Z. Peng, S. Yoo, D. Yu, D. Huang and H. Qin, Cloud motion estimation for short term solar irradiation prediction. 2013 IEEE International Conference on Smart Grid Communications (SmartGridComm), pp. 696-701, 2013. https: //doi.org/ 10.1109/SmartGridComm. 2013.6688040

[23] J. Shi and C. Tomasi, Good features to track. Proceedings of the IEEE Computer Society Conference on Computer Vision and Pattern Recognition, pp. 593 600, 1994. https://doi.org/ 10.1109/CVPR.1994. 3237 94

[24] C. Harris and M. Stephens, A combined corner and edge detector. Alvey vision conference, 15(50), pp. 105244, 1988.

[25] J.L. Barron, D.J. Fleet and S.S. Beauchemin, Performance of optical flow techniques. International journal of computer vision, 12(1), 43-77,1994. https://doi.org/10.10 07/BF 01420984

[26] A. S. Keçeli ve A. Kaya, Optik akış görüntüsü ve bilstm ile şiddet içeren hareketlerin sınıflandırılması. Avrupa Bilim ve Teknoloji Dergisi,14, 204-208, 2018. https://doi.org/10.31590/ejosat.460257

[27] Z. El Jaouhari, Y. Zaz and L. Masmoudi, Cloud tracking from whole-sky ground-based images. 3rd International Renewable and Sustainable Energy Conference (IRSEC), pp. 1-5, 2015. https://doi.org/ 10. 1109/IRSEC.20 15.7455105 